\title{
D-Learning Model for Knowledge Management in Enterprise 2.0
}

\author{
http://dx.doi.org/10.3991/ijac.v7i1.3506 \\ Amrous Naila, Daoudi Najima, Elghomari Khadija, Ettaki Badia \\ ESI (Ecole des Sciences de l'information), Rabat, Morocco
}

\begin{abstract}
Managing knowledge and skills of an enterprise in the era of social and collaborative web has increased the difficulty of the process previously known in the field of KM. besides this, in the era of globalization on the one hand and the economic crisis on the other hand, the companies become increasingly competitive and the employees must be more qualified but also polyvalent. Therefore, company need more then even before to provide tools to employees to become able to create, share, distribute and re-use knowledge and skills. New opportunities for content management enterprise processes associated with distance learning offer a better alternative to processing, sharing and dissemination of tacit and explicit knowledge.
\end{abstract}

Index Terms-d-learning; knowledge management, enterprise 2.0; KM 2.0 tools; enterprise content management (ECM)

\section{INTRODUCTION}

Enterprise 2.0 is a new concept which reflects the use of technologies of Web 2.0 in the company. It is a work environment which supports the communication, the collaboration and the coproduction of the enterprise contents, knowledge and skills.

These implicit and explicit contents are an informational heritage extremely important for the employees and their company.

With the era of globalization on the one hand and the economic crisis on the other hand, the companies become increasingly competitive and the employees must be more qualified but also polyvalent. How to be able to share, exploit and re-use the knowledge and skills of a company? How to guarantee a better exploitation of the expert knowledge of a company? D-learning process via new technologies in perpetual evolution proves of great importance. We propose a model of training which aims to accompanying enterprise 2.0 to provide to their employees learning contents resulting from the explicit and implicit contents available within the companies. This model proposes a system of transformation of the implicit contents into explicit contents. Moreover, he proposes a reorganization of these contents at end to allow a better exploitation. The situated learning, activate learning and collaborative learning are pedagogical approaches in the heart of our system.

\section{ENTERPRISE 2.0}

The emergence of tools such as 2.0 (wikis, blogs, social networks, etc.) has changed the management of IT systems in enterprises with the development of collaborative technologies and the emergence of new forms of content consumption user. These tools require companies to re- think their ways of management, operation and business models to complete their transition to business 2.0, which does not only have the desire to accumulate data, but their availability collective organization and to facilitate the use of information and retrieval of relevant knowledge, sustain learning and collective intelligence are the solid pillars of a learning organization.

Thus, for the firm to ensure that a critical mass of users is evolving and gradually maximizes opportunities for value creation. It is expected to deploy a support effort for the evolution towards Enterprise 2.0 in order to be legitimized and not be treated as a mere fad.

Associate Web 2.0 and Enterprise 2.0 is supporting change. However, with Web 2.0, companies are experiencing a real upheaval of established models outgoing model hierarchy pyramid to cross over, especially communication and sharing [1].

\section{A. Enterprise 2.0 Definition}

There are many definitions of "Enterprise 2.0" but most definitions focus on certain common aspects, which include social features, interactions, collaborative tools and collective intelligence. The first broadly accepted definition of Enterprise 2.0 came from Andrew McAfee, who coined this term "Enterprise 2.0 is the use of emerging social platforms within companies, or between companies, their partners and customers." [2]: Otherwise, B. Duperrin proposes the following definition, "Enterprise 2.0 is the implementation of a set of resources for the emergence of dynamic brought by individuals in order to adapt the company to the challenges of the knowledge economy and societal changes under stress its culture and its context" [3].

Enterprise 2.0 is an environment characterized with the excessive use of Web 2.0 technologies. These tools enable employees to collaborate through computer-mediated communication and to form online communities, in which contributions and interactions are globally visible and persistent over time. These capabilities are crucial to supporting collaboration, knowledge transfer, as well as "learning organization" initiatives. Indeed, AIIM ${ }^{1}$ defines Enterprise 2.0 as" a system of web-based technologies that provide rapid and agile collaboration, information sharing, emergence and integration capabilities in the extended enterprise. Enterprise 2.0, thanks to new tools offered by web 2.0, is now communicant, social and Collaborative."[4]. The Figure 1 illustrates the Enterprise 2.0 concept.

\footnotetext{
${ }^{1}$ The Global Community of Information Professionals
} 


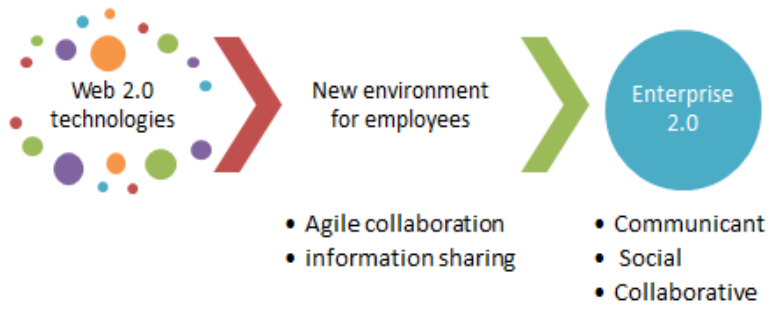

Figure 1. Enterprise 2.0 concept

\section{B. Enterprise 2.0 needs}

Enterprise 2.0 can't survive if it does not procure the ability to adapt continuously to turbulent economic environments.

Employees have to be able to transforming structured information into valuable knowledge at the same time they have to transform skills and knowledge in explicit information. The objective is to generalize the knowledge and skills of the company by creating the enterprise informational heritage.

The volume of information exchanged is increasing, which means a considerable amount of information and knowledge [5]. Thus, it would need to see several areas of knowledge capitalization on the same subject in different business units.

Therefore, the challenge for companies is the ability to store and query these gigantic volumes and disparate knowledge. But the real issue is the analysis and valuation of such knowledge and skills. Also management professionals information with their identification skills, treatment and recovery of information have a key role to play to support organizational changes caused by Web 2.0 role to help companies effectively manage their knowledge, their knowledge and skills, and then to assist them to make their system of governance efficient and responsive information.

\section{KNOWLEDGE MANAGEMENT IN THE ERA OF WEB 2.0}

The knowledge society, one that will allow a country to improve and enhance its performance, requires the synergy of knowledge. The Knowledge management (KM) is at the core of this synergy, which is in general, an approach that refers to all the processes put in place by an organization, to create, capture, manage, share and apply knowledge effectively, in order to create value, improve efficiency and achieve its strategic objectives. At present, the KM which accumulates systematically a maximum of knowledge disappears in favor of KM oriented information - Action. Activities are related to those "peoplecentric" instead activities centered on document « documents centric » [6].

Furthermore, the KM results today, with the creation and animation of "communities of practice" which represent a true meeting place and conversation, collaboration and sociability. Passing the constitution libraries of knowledge to those of expert networks. this is one of the best organizational contexts for a draft Social KM (SKM) to achieve its goals and fulfill this promise in enterprise. The latter should leave the only logical knowledge equals documents and enrich its ability to manage knowledge access to those who know. While working on four critical areas: "the location of knowledge and know-how, sharing

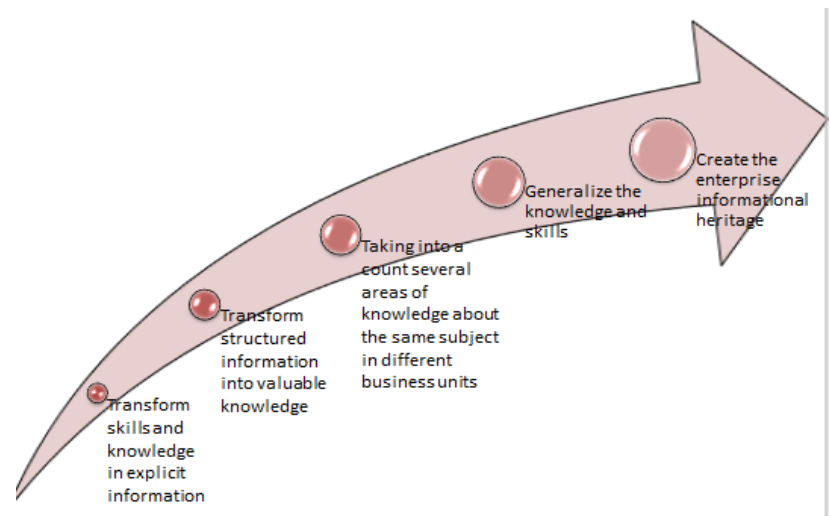

Figure 2. Some enterprise 2.0 needs

of expertise and resources, evaluation expertise and contributions and soliciting network via Questions/Answers" [7].

\section{A. Knowledge management 2.0}

Any change, whether big or small, may create a situation of instability, disorientation which can cause resistance, and sometimes a high level of stress. The phenomenon of resistance to change, in itself quite natural, may have several origins. Employees may not understand to see their functions, tasks and their jobs to change or disappear. The ease of sharing information and knowledge access can be seen as a source of challenge and positioning the organization holding the information being conventionally regarded as an attribute of power, as well as holding critical knowledge is associated with the indispensability [8].

The concept of Knowledge Management aims to establish a better organization within an enterprise company. It refers to the identification, valuation, capitalization and dissemination of knowledge, skills and expertise of the company and knowledge that come to it, in order to identify the most strategic and make them accessible [9].

In the era of Web 2.0 and collaborative tools, KM 2.0 allows maximum use of the knowledge and information held by the organization. KM 2.0 has a distinctive and competitive advantage for enterprise. Indeed, Web 2.0 has impacted many traditional KM to make a KM promoting interactions between individuals and groups, which creates an explosion of collaborative platforms where each becoming producer or co-producer.

\section{B. Knowledge transfer model}

Knowledge needs to be created, shared, distributed and applied continuously within the organization.

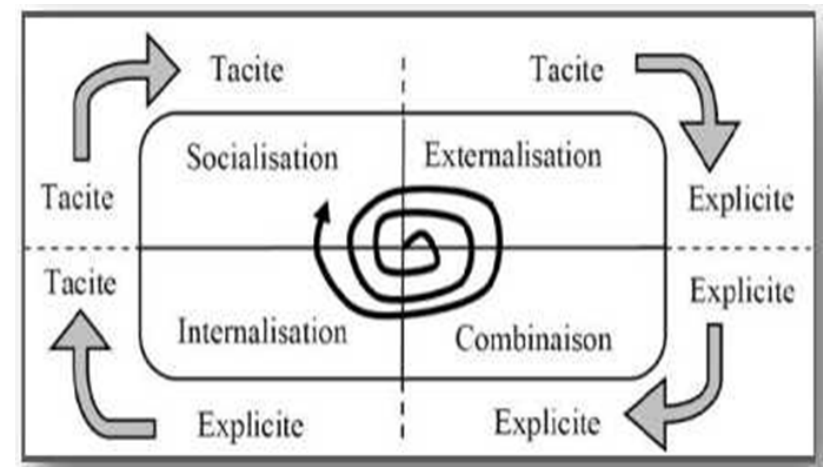

Figure 3. Model of conversion knowledge [10] 
Nonaka and Takeuchi developed a theory of organizational knowledge based on two dimensions: an "epistemological" dimension based on the distinction between explicit knowledge and tacit knowledge, and "ontological" dimension refers to the levels of knowledge creating entities (individual, group, organization). The interaction of the two dimensions of knowledge is achieved through four modes of conversion shown in Figure 3: socialization or direct transfer (tacit to tacit, from individual to individual), or internalization ownership (from tacit to explicit, organization to the individual), combination or sharing (of explicit to explicit, from the group to the organization) and externalization or explanation (from tacit to explicit, from the individual to the group) [11]. Knowledge management is a process that encompasses both the capitalization of knowledge sharing and appropriation of knowledge (reuse for creating new knowledge). This process is composed of four main stages as shown in the Figure 4.

Many are the tools for implementation of this process. Figure 5 is an overview of these tools.

The multitude of these tools contains a complexity and difficulty of implementation of the KM processes that remained for a long time limited to large companies. The web 2.0 technologies could reduce this complexity in the sense that they have a range of tools available as well as easy to use by employees of the company 2.0. However, content, knowledge and skills of Enterprise 2.0 are as rich and varied and need to be restructured to ensure a better reuse. For this purpose, we propose a system based on the d-learning model. This model is based on four phases of the KM process and offers new components and other stakeholders in the enterprise 2.0.

\section{D-LEARNING Model TO MANAGE EXPLICIT AND IMPLICIT KNOWLEDGE}

Enterprise 2.0 is favorable to the construction of knowledge and know-how, to share and exchange experiences and skills. The question that arises is how to facilitate the exploitation of this knowledge and experience in the era of web 2.0? Enterprise 2.0 requires a process adapted to the context of KM 2.0 technologies. Enterprise 2.0 has to be a learning company in order to guarantee its continued existence. We have to propose the importance of knowledge transfer in entreprise 2.0 via d-learning.

We define d-learning as a learning environment enabling all actors to perform tasks in their technological environment. Learning environment that ensures the quality improvement of the learning process, regardless of any constraints, offers services using the web and pedagogical approaches appropriate to the context of each actor.

D-learning can make huge forms of knowledge available to everyone, everywhere and whenever needed.

In Enterprise 2.0 as in any work environment, several types of knowledge have been proposed in the literature. I. NONAKA and H.TAKEUCHI distinguish two types of knowledge: those explicit and other tacit or implicit unstructured and difficult to communicate.

- Explicit knowledge: codified knowledge, transmitted in a formal and systematic language. They are clearly stated and physically transferable, because they are in the form of documents and are stored or disseminated on material information supports, such as libraries, archives and databases.

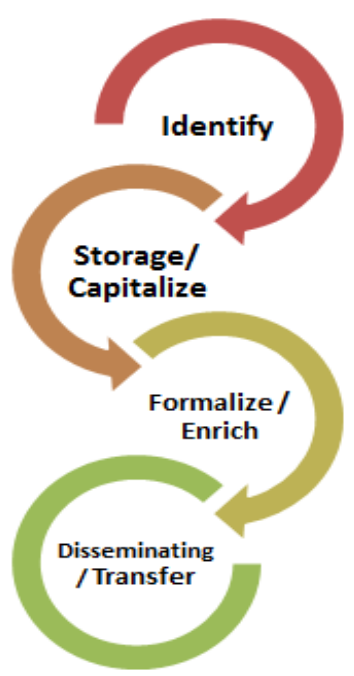

Figure 4. Knowledge Management processes

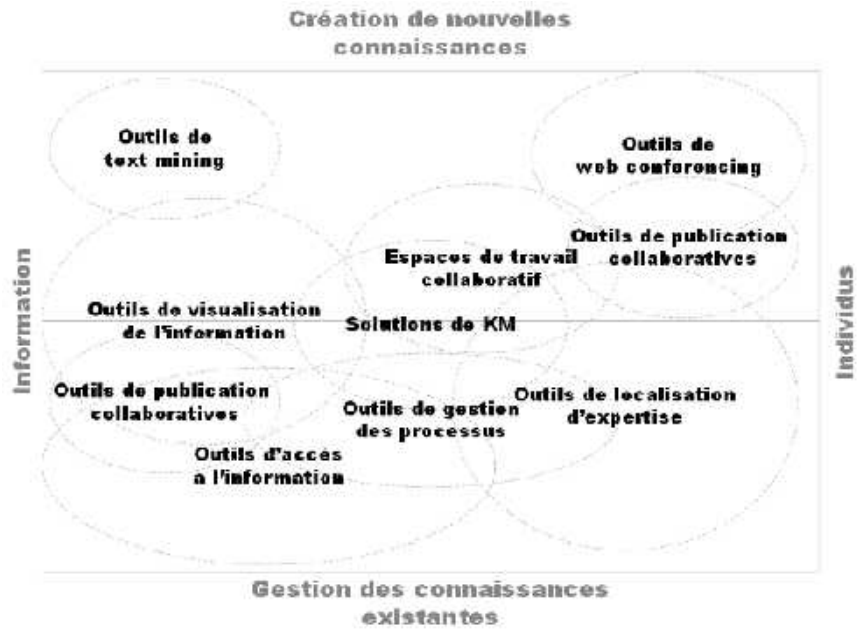

Figure 5. Some tools for implementation of KM process

- Tacit knowledge: include innate and acquired skills, Know-how and experience. They comprise, on the one hand, a cognitive component, namely mental models that humans form on the world, on the other hand, a technical component, namely the specific know-how, skills that apply in specific contexts, which makes them difficult to formalize, to extract and disseminate.

For the transfer of explicit and implicit knowledge, we propose a d-learning model based on an advanced tutorial and appropriate pedagogical approaches to each of these types of knowledge. We also suggest a model of communication between the actors of this new learning environment in enterprise 2.0.

\section{A. How to manage explicit knowledge by D-learning?}

To manage different types of explicit knowledge, we propose a distance learning model defined by four components: platform for knowledge management, the communication model, pedagogical approach and the tutoring system. These components are illustrated in the figure 6 . 


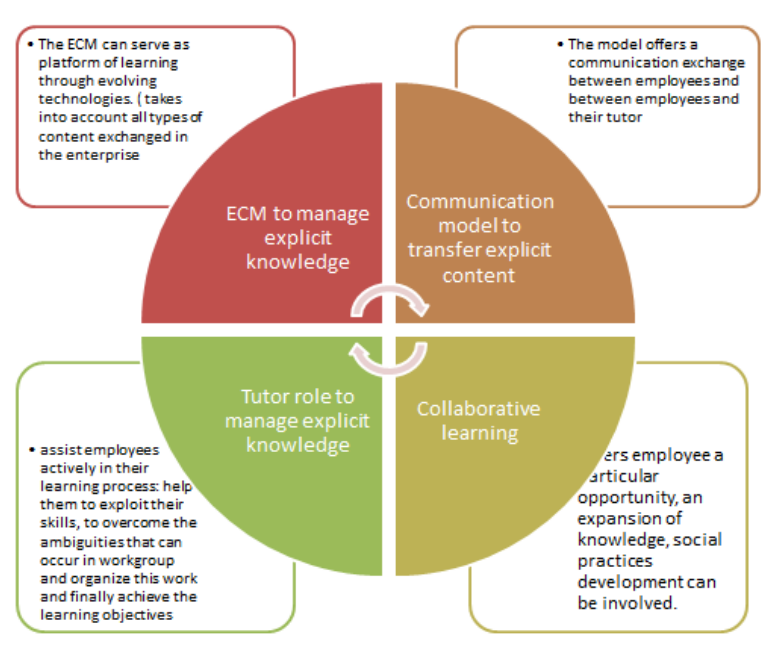

Figure 6. Mane component of d-learning serving to manage explicit knowledge

\section{1) D-learning using ECM to manage explicit knowledge}

D-learning is an environment of communication and exchange that provides content for learners to acquire knowledge, skills and attitudes. Content and explicit knowledge exchanged in the company can be considered as structured and unstructured content that can be managed by the tools proposed by ECM. Indeed, ECM is the strategies, methods and tools used to capture, manage, store, preserve and deliver content and documents related to organizational processes. ECM tools and strategies allow the management of an organization's structured and unstructured information, wherever that information exists [4]. ECM offers five essential components: web content Management, Record Management, digital asset Management, digital document management, content of social network and Mail Management. All of these components are very important for learning environment in order to ensure good qualities of learning [15]. Thus, we propose the use of ECM as a platform for aggregation and management of different types of explicit knowledge.

The ECM can serve as a platform of learning through evolving technologies. Indeed, it takes into account all types of content exchanged in the enterprise. The integration of a d-learning strategy allows the sharing and transfer of explicit knowledge so fluid and flexible.

\section{2) Communication model to transfert explicit content}

The communication is an essential component in enterprise 2.0. However, the communication flows in the era of Web 2.0 are rich and varied, so they may create an environment in which too much information which harms the information. D-learning provides a model for the capitalization of content based on the creation of reservoirs of content (content-warehouse). These contents are treated and structured by the tutor and experts. Thus, the model offers a communication exchange between employees, experts and tutor as shown in figure 7.

3) Collaborative learning pedagogical approach to share content

D-learning provides an environment of sharing and exchanging rich and varied content. However, the availability of content alone does not allow employees to acquire new skills. D-learning, in enterprise 2.0, must be based on

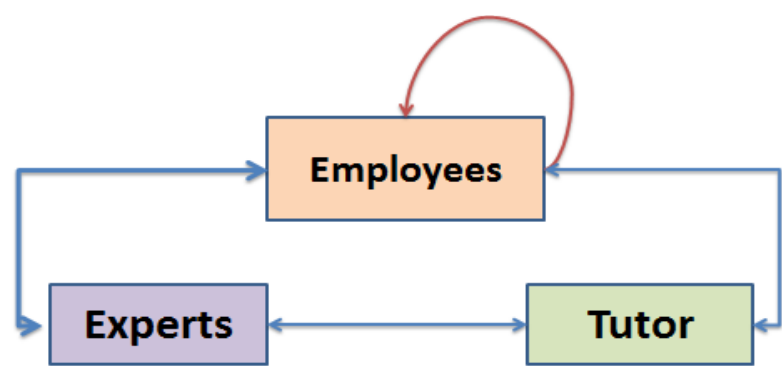

Figure 7. Communication model in d-learning for enterprise 2.0

workgroup that offers new opportunities and multiple benefits to employees and the company. Collaborative learning offers learner a particular opportunity, an expansion of knowledge, social practices development can be involved in teamwork. "The social interactions play according to Lebuis, Bednarz and Desgagne a key role in all learning or all acquisition of knowledge because they promote the failure of knowledge, the confrontation points of views, and enrichment of knowledge. The construction of knowledge has therefore much to gain from a collective elaboration process "[12].

\section{4) Tutor role to manage enterprise content}

Pedagogical approaches, privileged currently, focus on the learner who builds its own knowledge. However, this process does not exclude the presence of the tutor, who takes new responsibilities. In the model of d-learning proposed for enterprise 2.0, this actor can actively assist employees in their learning process in order to help them to exploit new skills, to overcome the ambiguities that can occur in workgroup and organize this work and finally achieve the learning objectives. To do this, it is based on listening, dialogue incentives and trusting relationship.

The tutor in the d-learning plays a very important role in the orientation and supporting employees in addition to making available content and skills. In Enterprise 2.0, its role will know a great evolution. As we have shown above, the company has several spaces for exchange and sharing content which is growing exponentially. We need to validate the centralization, the structure in order to better share and disseminate.

\section{B. How to manage implicit knowledge by d-learning}

As explicit knowledge, implicit knowledge should be transmitted and exchanged in a distance learning model adapted to the context of enterprise 2.0. We propose at first platforms for exchange and sharing, an appropriate communication model between actors of d-learning environment in the learning enterprise, adequate pedagogical approaches and a tutoring system which encourages the use of this type of knowledge.

\section{1) Social networks to explicit the implicit knowledge}

Tacit knowledge is ubiquitous. It is not localized organized and formalized. That's why we propose free communication spaces that can motivate employees to externalize and make collective rather than individual appropriation. An employee engagement process in the construction of information assets and collective competence is required. Enterprise 2.0 with private Web 2.0 technologies has offered employees spaces of exchange and open sharing. The lack of controls, freedom of expression in these environments is the only guarantee is the only guarantee for employees to express and exchange their knowledge and skills. 


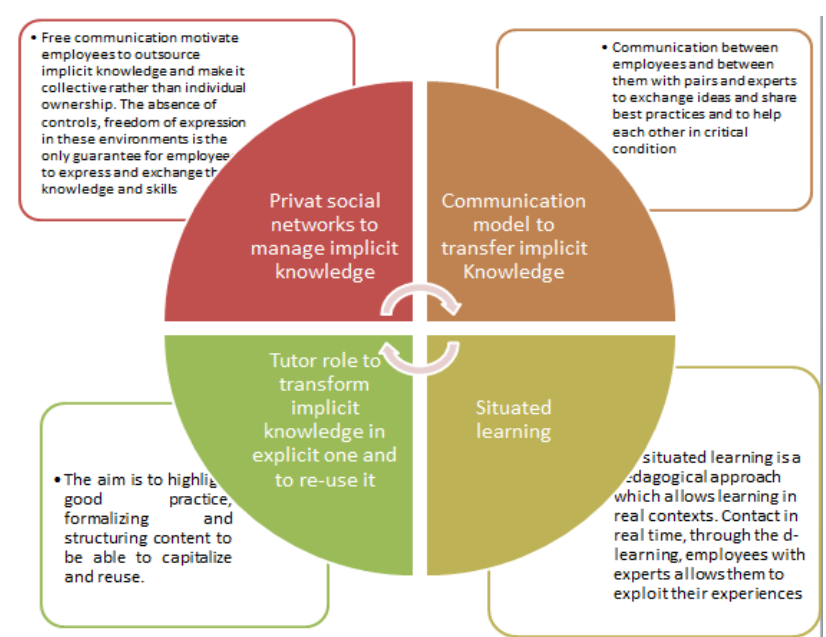

Figure 8. Mane component of d-learning serving to manage implicit knowledge

\section{2) Communication Model to manage implicit knowledge}

Each employee has his own knowledge and expertise. It is the same for peers and experts in the field of expertise. How to share experiences and structuring knowledge and skills to enable a better re-use? It is imperative to develop a model of communication between employees and between them with pairs and experts to exchange ideas and share best practices and to help each other in critical condition.

We propose a model of communication open to peers and experts in the fields of business besides employees and experts. This model is illustrated in figure 9.

The presence of the tutor will not be exchanges with other actors but only the exploitation of these exchanges without any intervention.

\section{3) Situated learning to manage implicit knowledge}

Situated learning is the study of how human knowledge in the course of develops activity, and especially how people create and interpret descriptions (representations) of what they are doing [13].

Most of the time, knowledge and expertise are very difficult to transmitting. It is implicit knowledge of the company. In order to transfer and share them, the situated learning is a pedagogical approach which allows learning in real contexts. Contact in real time, through the dlearning, employees with experts allows them to exploit their experiences.

Experts and other employees will thus play the role of a tutor for the transfer of tacit knowledge because the daily contact with employees leads to the need of exchange. Exchanges when they are on platforms for collaborative work (groupware or social networks or at least email) allow traceability and therefore a reorganization of knowledge later by the tutor. The warehouse content of the learning enterprise 2.0' information assets can thus be enriched.

4) Tutor role to transform implicit knowledge to explicit one

If the role of the tutor has evolved in the era of Web 2.0 , this role still knows other mutations to transform tacit knowledge in enterprise 2.0. The aim is to highlight good practice, formalizing and structuring content to be able to

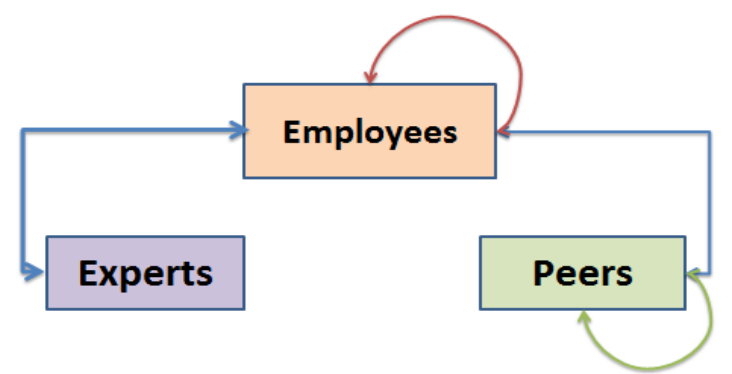

Figure 9. Communication model in d-learning for exchange implicit knowledge

capitalize and reuse. To do this, he may use content mining tools. [14].

The tutor is supposed to access, manage and restructure the content of exchanges between different actors in the enterprise 2.0 (employees, experts, peers).

\section{CONCLUSION}

Managing knowledge and skills of an enterprise in the era of social and collaborative web has increased the difficulty of the process previously known in the field of KM. However, new opportunities for content management enterprise processes associated with distance learning offer a better alternative to processing, sharing and dissemination of tacit and explicit knowledge. Our proposition centered on employees who can exchange and capitalize their knowledge and skills and create enterprise heritage with the help of experts, peers and tutors. The communication model provides an excellent opportunity to explicit the tacit knowledge. Integration of pedagogical approaches specially collaborative and situated learning enhances the exchange between all actors of the dlearning model in enterprise 2.0. Thanks to the component of this model, enterprise 2.0 can create a real

\section{REFERENCES}

[1] LECKO. A chacun son nouveau monde [en ligne]. http://www.lecko.fr

[2] McAfee, A. (2006). Enterprise 2.0: The Dawn of Emergent Collaboration. MIT Sloan Management review. Vol. 47, No. 3, p. 21-28

[3] http://www.duperrin.com

[4] AIIM, http://www.aiim.org/

[5] APROGED. Content analytics: les règles de l'art, janvier 2013[online]. http://www.aproged.org/aprogedv2/index.php/esp ace-de-telechargement-aproged/lb-content-analytics-aproged

[6] PREVEL, Pierre. Le KM, une préoccupation fort ancienne mais toujours d'actualité. Documentaliste-Sciences de l'Information, 2012. Op.cit. p. 24

[7] JACQUETY, Chloé. Communauté de Pratique et Social KM : le duo gagnant [online]. http://www.vedalis.com/fr/social- km

[8] CEFRIO. Les usages du Web 2.0 dans les organisations [online]. http://www.cefrio.qc.ca/projets.../projet-les-nouveaux- usages-duweb-20/

[9] Introduction to Knowledge Management [on line]: http://www.unc.edu/ sunnyliu/inls258/ Introduction_to Knowledge_Management.html

[10] NONAKA, I, TAKEUCHI, H. The knowledge creating company. Oxford University Press, 1995.Cités par : BALMISSE, G. Gestion des connaissances : outils et applications du knowledge management. Vuibert, Paris, 2002, p. 18

[11] Viola, Jean-Michel, « La gestion des transferts de connaissances entre générations ", $\mathrm{BBF}, 2005, \mathrm{n}^{\circ} 3, \mathrm{p} . \quad 5-10$ [online] http://bbf.enssib.fr/ 
[12] Cité dans Mémoire de maîtrise en éducation, université du Québec à chicoutemi : « Le style d'apprentissage : un outil de formation d'équipes de résolution de problèmes au niveau collégial », Annette Huot, Juillet 1997

[13] Clancey,W.J. (1995) A tutorial on situated learning. Proceedings of the International Conference on Computers and Education (Taiwan) Self, J. (Ed.) Charlottesville, VA: AACE. 49-70, 1995

[14] N. Daoudi, R. Ajhoun. Tutoring 2.0: how to improve tutoring system by using web mining? Proceding of INTED 7th International Technology, Education and Development Conference, Spain, Valencia, March 2013.

[15] N. Daoudi. How ECM can be used for distance learning content management ECM to LCM. Interactive Mobile and Computer Aided Learning (IMCL), Jordan. November. 2012.

\section{AUTHORS}

Amrous Naila, Daoudi Najima, Elghomari Khadija, and Ettaki Badia are with the Dept of Information System Management, Information Sciences Institute, ESI (Ecole des Sciences de l'information), Rabat, Morocco.

This article is an extended and modified version of a paper presented at the 16th International Conference on Interactive Collaborative Learning (ICL2013) and 42nd IGIP International Conference on Engineering Pedagogy, held from 25 to 27 September 2013 at Kazan National Research Technological University, in Kazan, Russia. Submitted 03 January 2014. Published as re-submitted by the authors 04 April 2014. 